\title{
Katrin Gaßnner
}

\section{Die Rechtsprechung zur Versammlungsfreiheit im internationalen Vergleich}

Eine Analyse anhand von Entscheidungen des Bundesverfassungsgerichts, des EGMR, des EuGH, der Obersten Gerichtshöfe der Russischen Föderation und des U.S. Supreme Courts

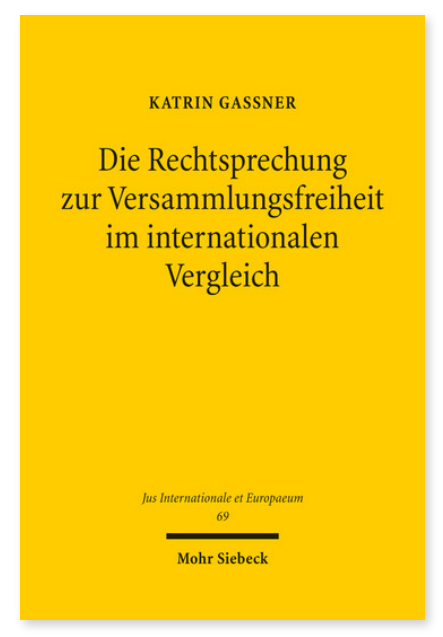

2012. XX, 400 Seiten. JusIntEu 69

ISBN 978-3-16-152156-0

DOI 10.1628/978-3-16-152156-0

eBook PDF $89,00 €$

ISBN 978-3-16-151867-6

fadengeheftete Broschur $89,00 €$
Die Versammlungsfreiheit ist in nahezu allen Rechtsordnungen weltweit zumindest formal gesichert und schützt ihrerseits die besondere Form der Kommunikation mit anderen durch das Zusammenkommen und die gemeinsame Äußerung von Ansichten in vielfältigster Form. Katrin Gaßner versucht, dies für einige ausgewählte Gerichte näher zu beleuchten. Dabei geht es nur am Rande um die theoretischen Grundlagen. Im Fokus steht vielmehr die rechtsanwendende Praxis verschiedener oberster Gerichtshöfe - des Bundesverfassungsgerichts, des Europäischen Gerichtshofes für Menschenrechte, des Europäischen Gerichtshofes, des United States Supreme Courts und der obersten Gerichtshöfe der Russischen Föderation. Die Autorin stellt allgemeine Grundsätze, Gemeinsamkeiten und Unterschiede in der Rechtsprechung, aber auch den Wandel der Rechtsprechung über die Jahre hinweg sowie etwaige Überschneidungen mit den jeweils anderen Rechtsordnungen dar.

Katrin Gaßner Geboren 1977; Studium der Rechtswissenschaften in Bonn und Straßburg; Forschungsaufenthalte an der Staatlichen Universität St. Petersburg und der Boston University; 2004-06 Referendariat in Bonn; seit 2006 Rechtsanwältin (Principal Associate) in Düsseldorf.

Jetzt bestellen:

https://mohrsiebeck.com/buch/die-rechtsprechung-zur-versammlungsfreiheit-im-internationalen-vergleich-9783161521560? no_cache=1

order@mohrsiebeck.com

Telefon: $+49(0) 7071-923-17$

Telefax: +49 (0)7071-51104 